\title{
Antinoite and Hermopolite Villages and Requisitions
}

\author{
Nikolaos Gonis*
}

\begin{abstract}
Editions of two papyri of the British Library with lists of villages from the areas of Antinoopolis and Hermopolis.

Keywords: Villages, Antinoopolis, Hermopolis, requisitions, fodder, building works

https://doi.org/10.1515/apf-2019-0016

The two papyri published below contain lists of villages, many of them new, which were required to provide goods or men for the needs of the government. 1 probably and $\mathbf{2}$ certainly belong to the early Islamic period.

The papyri are kept in two different departments of the British Library, Western (1) and Oriental Manuscripts (2). 1 was formally accessioned in 1910 but had entered the British Museum some years earlier, presumably with papyri acquired from Ch. Murch. ${ }^{1} \mathbf{2}$, whose other side was published as P.Lond. Copt. I 1073, also came through Murch.
\end{abstract}

\section{Antinoite fodder}

BL Pap. 1869

$8.2(\mathrm{w}) \times 16.6 \mathrm{~cm}(\mathrm{~h})$

Mid seventh century

The papyrus preserves the left-hand part of a list of requisitions of fodder

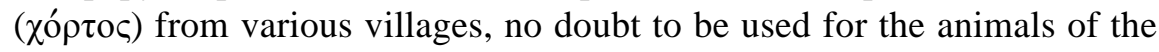
army or generally the administration. The text is broken off after the names of the villages, which may have been followed by the quantities of

\footnotetext{
* Kontakt: Nikolaos Gonis, Department of Greek and Latin, University College London, GB-London WC1E 6BT, <n.gonis@ucl.ac.uk>

${ }^{1}$ See Catalogue of Additions to the Manuscripts in the British Museum in the years MDCCCCVI-MDCCCCX (1912) 315 (cf. 314). Additional information was supplied by Federica Micucci, whom I thank. - The images are reproduced by permission of the British Library Board.
} 
fodder that were due from each of them; cf. SPP X 83 (VIII), which refers to Arsinoite villages and bundles of hay. The hand suggests a date around the middle of the seventh century; it is likely but not certain that the text post-dates the Arab conquest. Requisitions of fodder (dry hay) are mentioned in W.Chr. 8.15, written on the eve of the conquest (639/40). For contemporary registers of requisitions headed by the term $\delta 1 \alpha v o \mu \eta$, see CPR XXX 32.1 and $n$.

About half of the sixteen toponyms that can be read in the papyrus make their first appearance here. The others are generally sparsely attested, but most of them were known to be located in the area of Antinoopolis. This would have been a list drawn up at the level of the pagarchy.

The text is written along the fibres in ink now turned brown. Check marks (short obliques or dots) are placed opposite most entries. On the back, written across the fibres and upside down in relation to the text on the front, are the beginnings of several lines starting $\alpha[$. The text at its greatest extent reads $\alpha \pi \mathrm{o} \lambda[$, presumably $\alpha \dot{\jmath} \mathrm{o} \Lambda[$; it may have been another list of villages (cf. text 2 below).

There is a sheet join $c .2 \mathrm{~cm}$ off the left-hand edge on the front.

$\dagger \delta 1 \alpha v o \mu(\grave{\eta}) \chi o ́ \rho \tau(\mathrm{ov}) \tau \hat{\omega} v \alpha[$

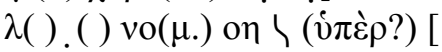

4

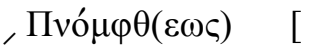

„Ає

, В $\alpha \rho \beta \alpha \rho i ́ o v$

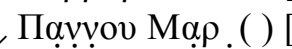

,'I $\beta \mathrm{t} \hat{\omega}(\operatorname{voc})$ " $\Omega \rho o v[$

8

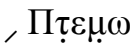

[

, $\Lambda$ $\sigma ı \delta о \varsigma,(\kappa \alpha i) ~ П \alpha \gamma .[$

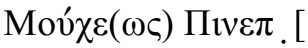

'A $\alpha \dot{\beta} \omega v$

12

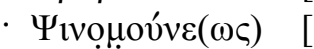

- $\Sigma \varepsilon ́ \rho \varepsilon \omega \varsigma$

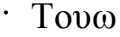

$\Theta \mu о v \rho \eta ́ \sigma \varepsilon(\omega \varsigma)$

16

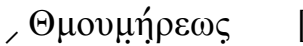

,$\Lambda v \sigma \alpha v[i ́$ ] ov

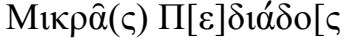

. ๘.[..]. . $\kappa() \pi()[$ 


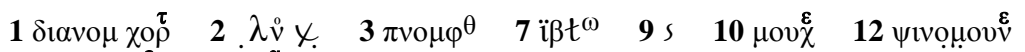

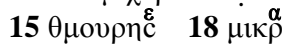

Requisition of fodder of ... 781/2 solidi, as follows:

Pnomphtheos ... Aeos ... Barbariou ... Pannou Mar- ... Ibionos Horou ... Ptemo ... Lysidos and Pag — ... Moucheos Pinep - ... Arabon ... Psinomouneos ... Sereos ... Touo ... Thmoureseos ... Thmoumereos ... Lysaniou ... Mikras Pediados ...

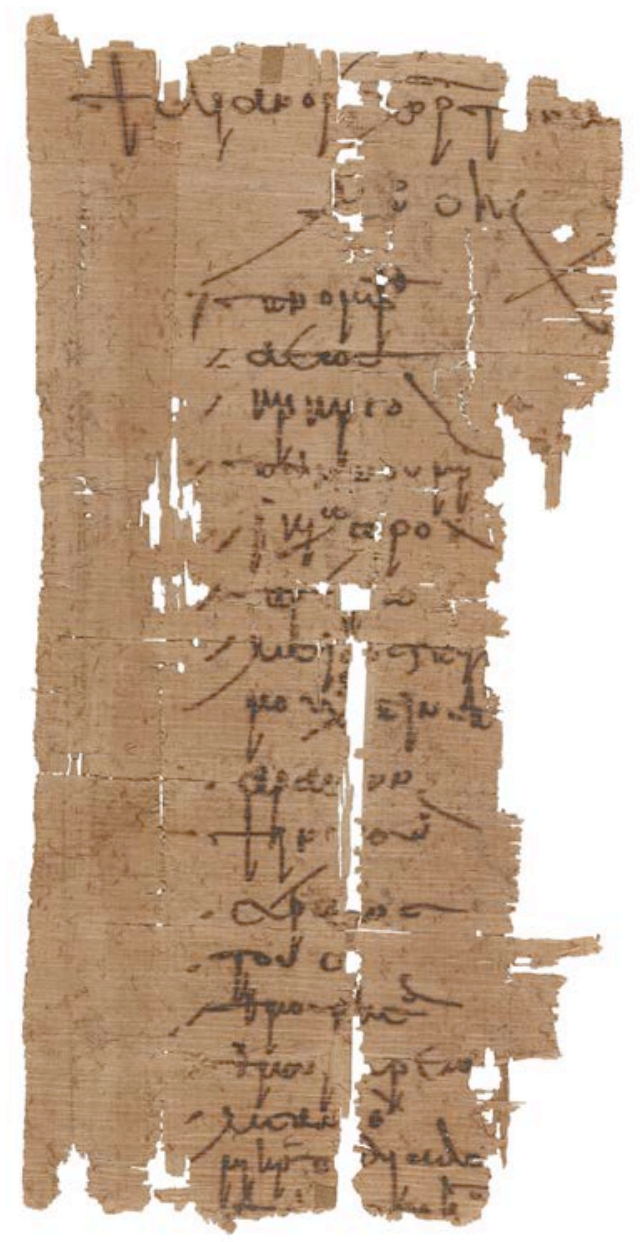

BL Pap. 1869 
$1 \delta 1 \alpha v o \mu(\grave{\eta}) \chi o ́ \rho \tau(o v)$. On $\delta 1 \alpha v o \mu \alpha i ́$ in general, see F. Mitthof, SPP III $^{2} .2$, pp. xxiii-xxiv.

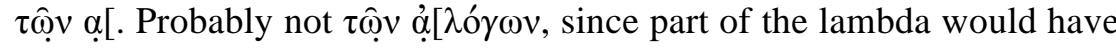
been visible (I owe the observation to F. Morelli).

$2 \lambda(\mathrm{ot}) \pi(\alpha)$ rather than $\lambda\left(\mathrm{o}^{\prime}\right) \gamma(\omega)$. The relation of this line to the previous is unclear, but it is likely that these $78 \frac{1}{2}$ solidi represent the cost of the requisitioned fodder; it is also possible that the requisitions were commuted into money.

3 Пvó $\mu \varphi \theta(\varepsilon \omega \varsigma)=$ TM Geo ID 6792. See R. Ast, P.Jena II, p. 43.

4 'A $\varepsilon \omega \varsigma$ = TM Geo ID 9318, from P.Leid. Inst. 72.3 (the suggestion to read ${ }^{\circ} \mathrm{A}<\mathrm{K}>\varepsilon \omega \varsigma$ [BL X 116], should be abandoned). Another attestation is offered by SB XXVI 16491.i.3, originally read as 'A . . , but on an image it is possible to read 'Aєฺ̣ ૬.

5 B $\alpha \rho \beta \alpha \rho i ́ o v$. New. There was a village of this name in the Fayum (TM Geo ID 399), and a monastery in Aphrodito (TM Geo ID 3760).

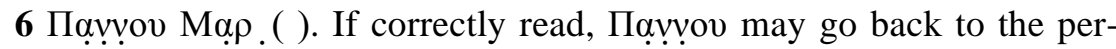
sonal name Пavvov̂ (TM Nam ID 4848), which however is not attested in this area. The suprascript character after $\rho$ is either $\varepsilon$ or $v$. Whatever the precise reading, this is a new toponym.

7 'I $\beta 1 \hat{\omega}(v o \varsigma)$ " $\Omega \rho o v$. Another new locality, unless it was mentioned in the Antinoite SB XXVI 16491.ii.3 ('I $\beta 1 \hat{\omega} v o[\varsigma$ ). There are numerous villages in the area of Hermopolis called 'I $\beta 1 \omega v$ + name; see M. Drew-Bear, Le nome Hermopolite (1979) 122ff.

$8 \Pi \tau \varepsilon \mu \omega$. Apparently new, but there is a Lycopolite locality called $\Pi \tau \varepsilon \mu \omega$ (TM Geo ID 3097).

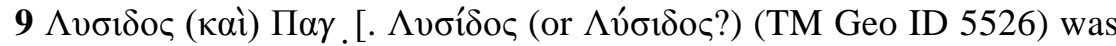
previously known from SB VI 9616v.23 (mid 6th c.). П $\alpha$ [ appears to be new.

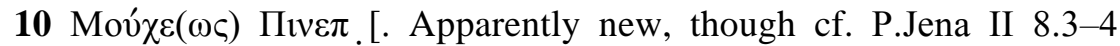

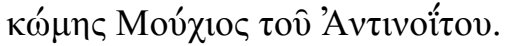

11 'A $\alpha \dot{\beta} \beta \omega v=$ TM Geo ID 2580. This text and SB XXVI 16491.10 add to the evidence that this was an Antinoite village. Drew-Bear, Le nome Hermopolite 68, knew it from two other documents. 


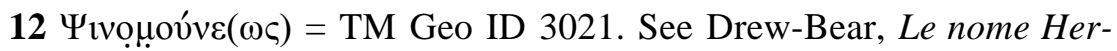
mopolite 328f.

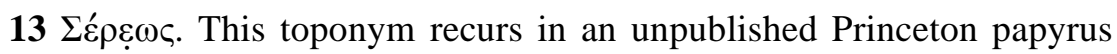
(Bell II 156a), edited by M. Houle.

14 Tovw. The likely location of this settlement in the environs of Antinoopolis rules out identifying it with any of the known places in the wider area of Hermopolis which have Touo or Toou in their names; cf. DrewBear, Le nome Hermopolite 305-308.

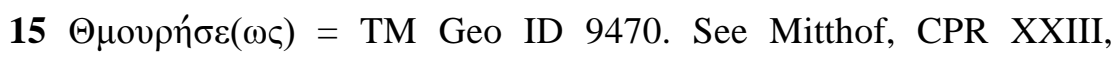
pp. 214f. with n. 3.

$16 \Theta \mu o v \mu \underline{\rho} \rho \varepsilon \omega \varsigma=\mathrm{TM}$ Geo ID 4521. Its Antinoite connections had been recognized by Drew-Bear, Le nome Hermopolite 114. It is mentioned with Pnomphthis and Arabon also in P.Ryl. Copt. 338 = SB I 5953.

$17 \Lambda v \sigma \alpha v[i$ [i]ov. The name of this locality is restored from the Princeton

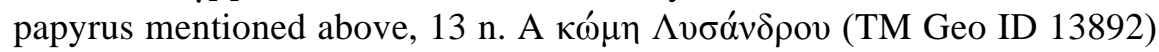
is known from SEG LVIII 1791.3, a sixth-century inscription from Antinoopolis, but the lacuna seems too small to accommodate $[\delta \rho]$.

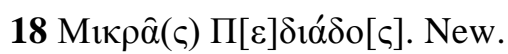

\section{Hermopolite men}

A piece cut from a fiscal register was reused for a legal document concerning an inheritance of land, published as P.Lond. Copt. I 1073 in 1905. There remain parts of three columns, broken off at the top and sides. Of the first column, only line ends with numbers are preserved; when verifiable, these are $\beta$ (twice) and $\gamma$.

In the second and third columns, toponyms are followed by personal names. Occupations are given twice: there is one carpenter and one builder (i 5,6). A number is added after the name of each village, indicating the number of persons connected with it. These would be men that each village had to provide for building projects of the state; the exact purpose 
would have been indicated in the heading, now lost. ${ }^{2}$ The persons for whom no occupation is given would have been unskilled labourers.

Check marks were added opposite each toponym. Eleven localities are mentioned, of which three or four are new. Those whose location is known were all situated in the southern part of the Hermopolite nome. It is conceivable that this list was drawn up in the administrative office of the

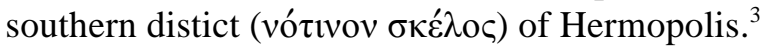

Col. ii

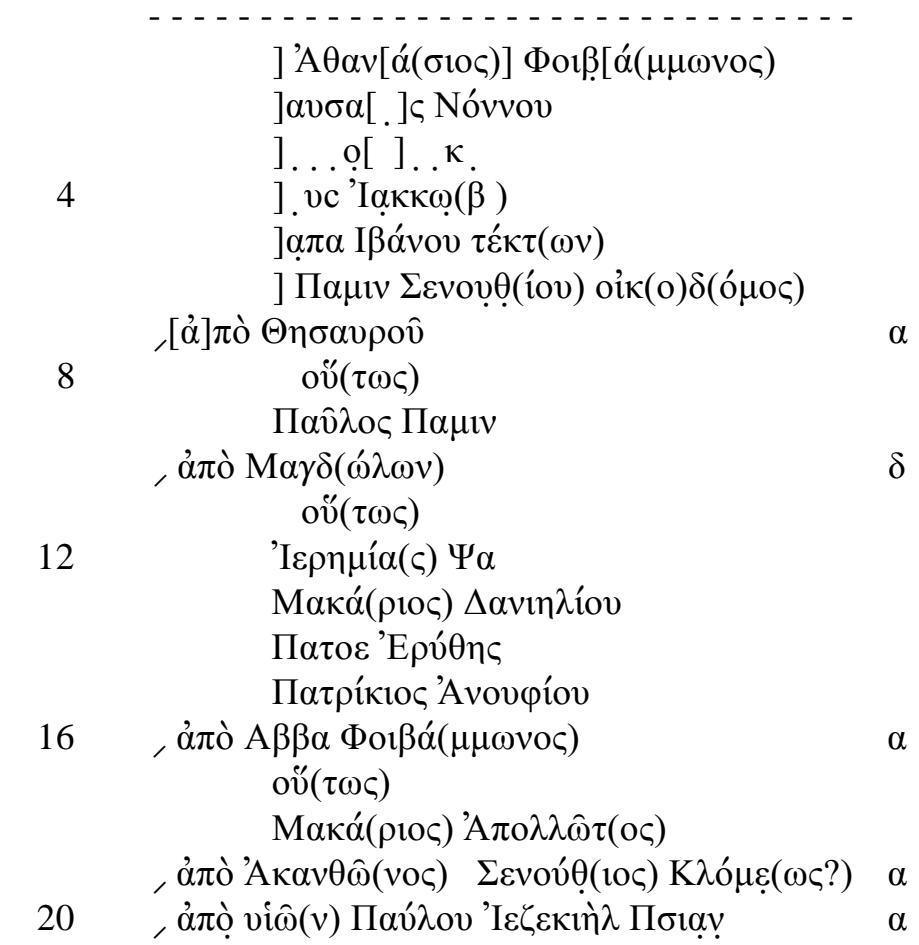

\footnotetext{
${ }^{2}$ A comparable text published very recently is P.CtYBR inv. 461, ed. L. Berkes \& B. Haug, 'Villages, Requisitions, and Tax Districts: Two Greek Lists from the Eighth-Century Fayyūm', BASP 53 (2016) 206-22. See also my 'P.Vindob. G 14965 (= CPR IX 67) + 18880: Requisitioned Workers in Eighth-Century Egypt', ZPE 145 (2003) 209-11, with references.

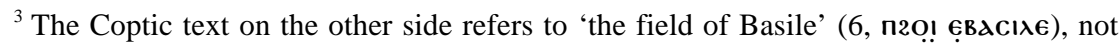
to be confused with settlements of this name in the area of Hermopolis.
} 


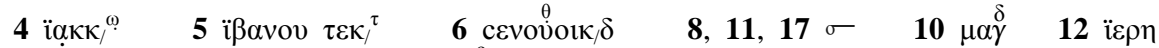

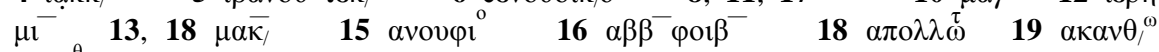

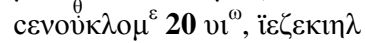

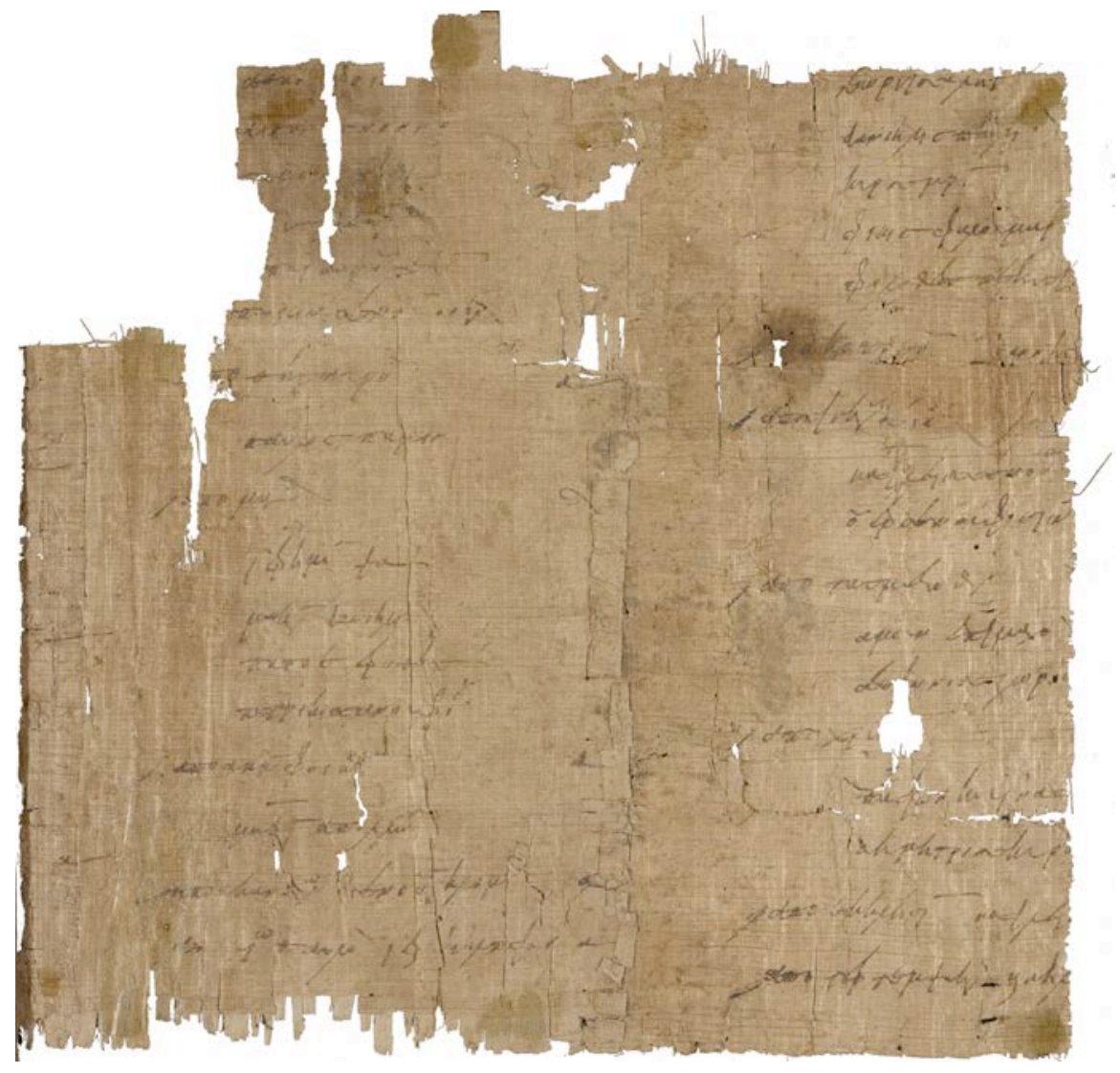

BL Or. 6056

Col. iii

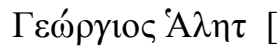

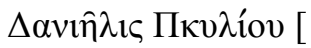

4

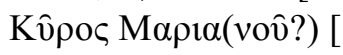

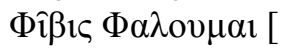

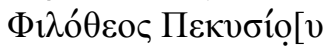




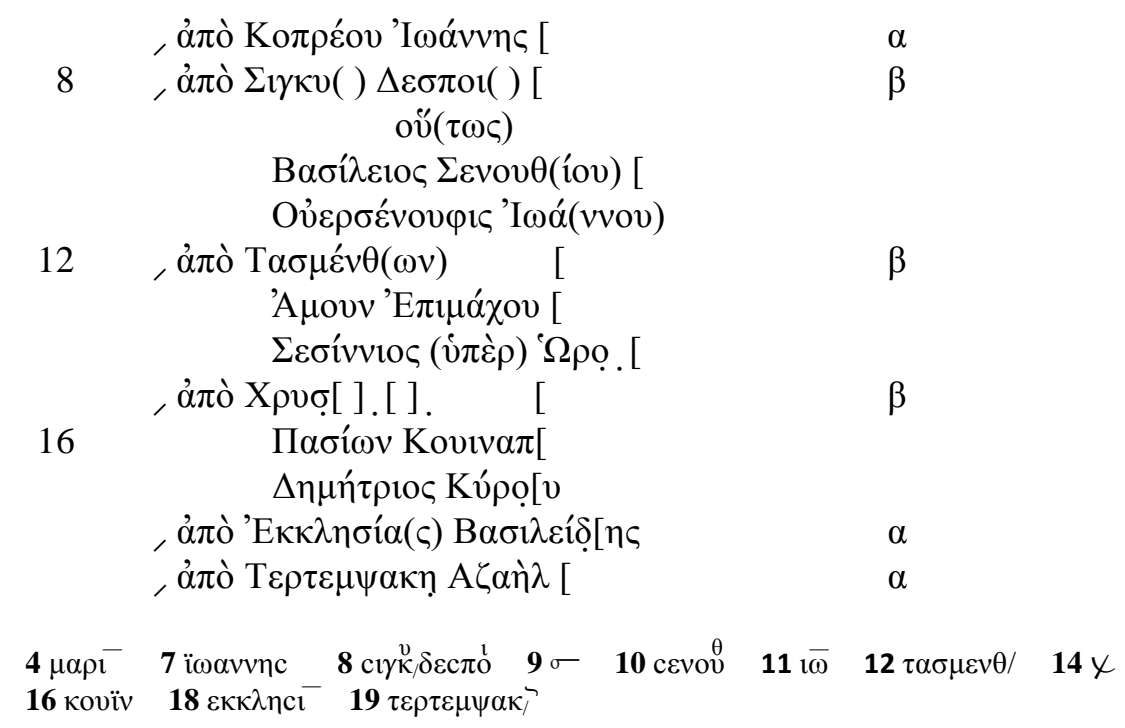

(col. ii)

Athanasios son of Phoibammon

- ausa - son of Nonnos

—us son of Iakob(ios?)

... (son of?) (?)Apa Ibanos, carpenter

Pamin son of Senouthios, builder

From Thesauros

as follows:

Paulos son of Pamin

From Magdola

as follows:

Ieremias son of Psa

Makarios son of Danielios

Patoe son of Erythes

Patrikios son of Anouphios

From Abba Phoibammon

as follows:

Makarios son of Apollos

From Akanthonos Senouthios son of Klome 1

From the sons of Paulos Iezekiel son of Psian 1 
(col. iii)

Georgios son of Halet

Danielis son of Pkylios

Kyros son of Marianos(?)

Phibis son of Phaloumai

Philotheos son of Pekysios

From Kopreou Ioannes (son of ...) 1

From Sinky( ) Despoi( )

1

as follows:

Basileios son of Senouthios

Ouersenouphis son of Ioannes

From Tasmenthon

Amoun son of Epimachos

Sesinnios on behalf of Horo-

From Chrys-

Pasion son of Kouin from(?)

Demetrios son of Kyros

From Ekklesias $\quad$ Basileides (son of ...) $\quad 1$

From Tertempsake Azael (son of ...) 1

Col. ii

3 ]. . . . Apparently not oik(o) $\delta(o ́ \mu \circ)$. (The writing further to the left which is visible on the image is on a loose fragment moved there. It is less likely that it represents a number.)

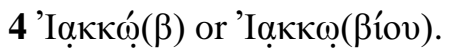

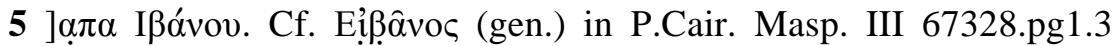
(521). This may be the name of the carpenter and not of his father: there is not much room in the break.

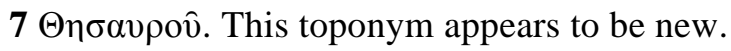

$10 \mathrm{M} \alpha \gamma \delta(\omega \hat{\lambda} \omega v)$. M $\alpha \gamma \delta \omega \dot{\lambda} \omega v$ is usually followed by another name, and Drew-Bear, Le nome Hermopolite 157, points out that it is uncertain whether a village called simply Magdola existed in the Hermopolite nome, concluding that 'il est toujours possible de supposer que le complément distinctif est perdu ou sous-entendu'. No Magdola + name is attested in the south of the nome, but M $\alpha \gamma \delta \omega \hat{\lambda} \omega v$ without further qualification is listed with villages of Leukopyrgites Kato in BGU II 552, 555, and XI 
2136, all three of the late third century; this is the toparchy to which other localities mentioned in our text used to belong. It is probably relevant that

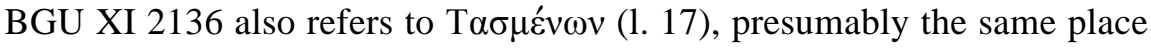
as $T \alpha \sigma \mu \varepsilon v v \theta(\omega v)$ at iii 12 here.

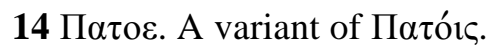

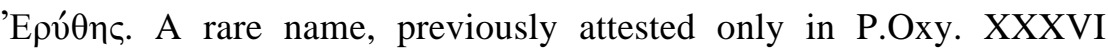
2778.16 (II/III) 'E

16 A $\beta \beta \alpha$ Фoı $\beta \alpha ́(\mu \mu \omega v o \varsigma)=$ TM Geo ID 7945. Cf. CPR IV 170.18 غ̇лоıк(iov) 'A $\beta \hat{\alpha}$ Фoı $\beta \alpha ́ \mu \mu \omega(v \circ \varsigma)$. It is unclear whether all place names and religious institutions associated with St Phoibammon and located in the hinterland of Hermopolis refer to the same place; see Drew-Bear, Le nome Hermopolite 318.

19 'A $\kappa \alpha v \theta \hat{\omega}(v \circ \zeta)$. There may have been more than one settlement of this name in the wider Hermopolite region (a single entry in Trismegistos, Geo

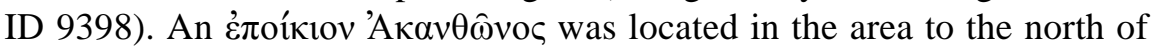
Hermopolis, not far from Tlethmis (see F. Morelli, CPR XXX 1.37 n., with the map on p. 116). This may tell against identifying the غ̇лоíкıov

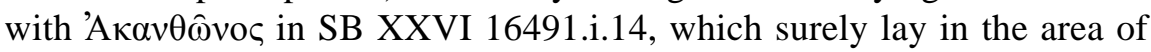
Antinoopolis. An Antinoite Akanthonos might be a better fit for the one here, which would have been situated in the south; but the identification would imply that the borders of the pagarchies were fluid, since the other localities in our text cannot have been Antinoite.

$\mathrm{K} \lambda \hat{o} \mu \varepsilon(\omega \varsigma$ ?). The name $\mathrm{K} \lambda \hat{\omega} \mu \iota \varsigma$ is attested in Hermopolite documents.

20 vîิ

Пбıа. The name is not known, even if the reading is doubtful.

Col. iii

$1 \mathrm{~A} \lambda \eta \tau$ corresponds to $2 \lambda \lambda \mathrm{HT}$, attested in documents from Upper Egypt (TM Nam ID 27362).

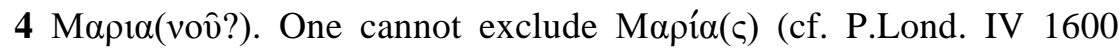
introd.) or even Maplá( $\mu$ ov) (cf. J.-L. Fournet, ZPE 142 (2003) 195).

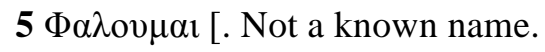




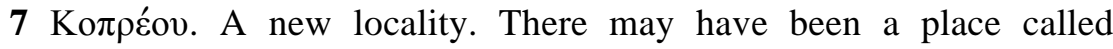

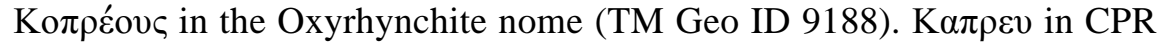
XXX 1.54 was located in the north of the Hermopolite nome.

The numbers restored at the end of this line and below, in 8, 12, 15, 18, and 19, follow the pattern in columns i and ii.

$8 \Sigma \gamma \gamma \kappa \nu($ ) $\Delta \varepsilon \sigma \pi \mathrm{ol}($ ). Perhaps $\Sigma$ $ү \kappa v ́(\rho \kappa \varepsilon \omega \varsigma)$, a village located in Leukopyrgites Kato, in the south of the nome, and identified with modern Senguerg (TM Geo ID 7128; Drew-Bear, Le nome Hermopolite 242, s.v. $\Sigma \varepsilon v \kappa u ́ \rho \kappa \varepsilon(\varsigma)$. A potential difficulty is that the spelling with -кv- is not attested after the third century. $\Delta \varepsilon \sigma \pi \mathrm{ol}($ ) probably stands for $\Delta \varepsilon \sigma \pi \mathrm{ol}(v i \kappa)$, indicating the property of an empress in earlier years (cf. B. Palme, P.Harrauer, p. 234 n. 4).

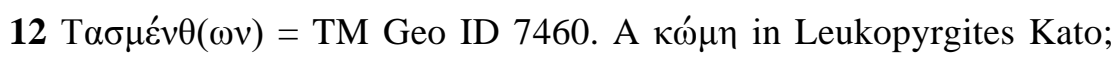
see Mitthof, P.Paramone $18.13 \mathrm{n}$.

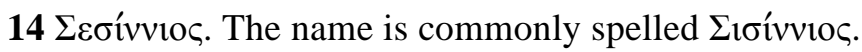

(vं $\pi \dot{\varepsilon} \rho)$ ' $\Omega \rho o$. [. The letter on the edge hardly admits $v$ (otherwise, the name would probably be $\Omega \rho o v$ [ $\omega \gamma \chi$ íov). Sesinnios would perform service on behalf of Horo-

$15 \mathrm{X} \rho v \sigma[]$ ]. [ ]. The traces are not an easy match with an abbreviated

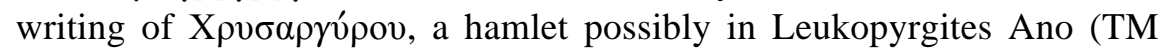
Geo ID 8073; Drew-Bear, Le nome Hermopolite 322); the suprascript letter suggests $\alpha$ rather than $v$.

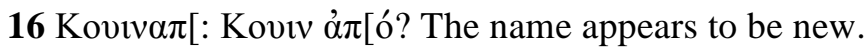

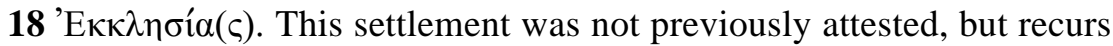

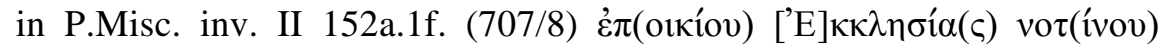

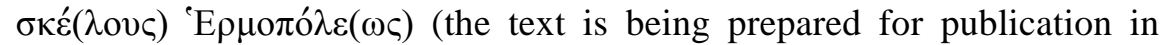

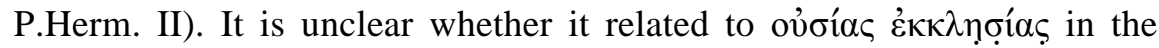
fourth-century P.Herm. Landl. 1.534.

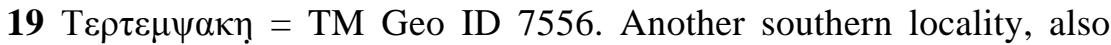
once in Leukopyrgites Kato; see Drew-Bear, Le nome Hermopolite 287f.,

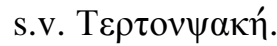

'A $\alpha$ 门́ $\lambda$. The name is otherwise known only from Coptic documents (TM Nam ID 27293). ${ }^{4}$

\footnotetext{
${ }^{4}$ I am grateful to Federico Morelli for comments on a draft of this paper.
} 